\title{
Governing Big Data
}

\author{
Andrej J. Zwitter ${ }^{1, *}$ and Amelia Hadfield ${ }^{2}$ \\ ${ }^{1}$ Faculty of Law, University of Groningen, Oude Kijk in 't Jatstraat 26, 9712 EK Groningen, The Netherlands; \\ E-Mail: a.zwitter@rug.nl \\ ${ }^{2}$ Department of Psychology, Politics and Sociology, Canterbury Christ Church University, North Holmes Road, \\ St. Martin's Priory, Canterbury, CT1 1QU, UK; E-Mail: amelia.hadfield@canterbury.ac.uk
}

* Corresponding author

Submitted: 10 January 2014 | Published: 20 January 2014

\begin{abstract}
: 2.5 quintillion bytes of data are created every day through pictures, messages, gpsdata, etc. "Big Data" is seen simultaneously as the new Philosophers Stone and Pandora's box: a source of great knowledge and power, but equally, the root of serious problems.
\end{abstract}

Keywords: Big Data; privacy; research

2.5 quintillion bytes of data are created every day through pictures, messages, gps-data, etc. [1]. "Big Data" is seen simultaneously as the new Philosophers Stone and Pandora's box: a source of great knowledge and power, but equally, the root of serious problems. While corporate and public agencies have long been concerned with this phenomenon since the beginning of the communication age, the debate about big data has recently risen in prominence as a result of the NSA Prism scandal, itself something of a follow-on from the Wikigate and Edward Snowden saga. Among one of the most prominent current challenges in contemporary politics is the question of how to deal with big data. The recent Snowden revelations about NSA surveillance of foreign heads of states have caused international tensions between Indonesia and Australia [2], Brazil and Germany, the latter levelling accusations at the United States of America, with backlashes from a range of EU actors, and indeed the United Nations General Assembly [3]. Following on from our previous editorial, in which we debated the challenges associated with open access publishing, we now briefly explore the ways in which Big Data-as a polyvalent empirical research tool-and its associated issue of attenuated or enhanced Data Security now confronts current researchers in the area of governance and politics.

The 'inputs' of Big Data are generated on a daily basis-largely involuntarily by individuals in the process of simple and complex interactions with all forms of information communication technology (ICT). The 'outputs' of Big Data, however, are more troublesome to understand. A vast majority is clearly being deliberately accrued and retained by a wide range of commodity and financial service providers, as well as those in the internet and wider security sectors (data harvesting). In contrast to traditional datasets for statistical analysis based on purposely selected variables, Big Data is the accumulation of purposefully selected and random data of individuals and groups, longitudinal data, and many other forms of information. The use of Big Data in various forms (e.g. data mining) reveals clear and interesting profiles about individuals, and indeed groups, when consolidated into data pools in longitudinal form. Illustrating economic, social, and even political and cultural preferences, as well as personal identification, much of a highly sensitive nature, Big Data researchers now have access to a seemingly endless swathe of sensitive information, the collection 
of which would-prior to the unregulated impunity of the Big Data age-likely have been prohibited by any decent ethics committee. The behavioural algorithms generated via longitudinal data pools reveal the intimate sensibilities, preferences, and future likely procurement patterns and societal behaviour of individuals and groups in any range of geographical, political, sociocultural, religious and economic categories.

The negative ramifications are obvious. Much is taken without knowledge or consent, for the purposes of guiding, managing (largely online) commercial choice to ensure online consumers can easily buy exactly what they were looking for, and find it hard to resist buying a great deal that they weren't looking for. Hard on the heels of a global financial crisis that spun out of control largely due to chronically ill-informed consumers being peddled unsustainable mortgages and loans, Big Data gathering by both commercial and security actors (principally in North America and Europe) is the insidious spin-off of a private sector desperate to rebuild itself in the wake of such a macro-financial catastrophe.

But the positive potential is also enormous, from the perspective of basic data analysis within politics and governance studies. Raw data on personal, political, procurement patterns, suggest a new-found ability to look in-depth at a wide variety of social behaviour never previously attempted. Researchers in politics, governance, and international relations could indeed benefit from ethically-sound (i.e. anonymized and voluntarily provided) Big Data for distilling information about the interrelation between micro- and macro-level variables, combining individual, national and international actors, and shed empirical light on complex interactions previously hardly researchable.

Other 'political positives' suggest themselves, both via Big Data and from the untrammeled expansion of Social Media as a form of political communication and leverage. Clearly Big Data, and the ability to access, analyze and control based on the results, is a tremendous new source of political, economic, and even

\section{References}

1. Zicari RV. Big Data for Good. ODBMS Industry Watch. 4 June 2012. Available from: http://www.odb $\mathrm{ms}$. org/blog/2012/06/big-data-for-good (accessed on 10 January 2014).

2. Indonesia Freezes Cooperation with Australia over Phone Tapping. Deutsche Welle. 20 November 2013. Available from: http://dw.de/p/1ALAu (accessed on 10 January 2014).

3. Lynch C, Harris S, Hudson J. Exclusive: Germany, Brazil Turn to U.N. to Restrain American Spies. Foreign military power. Social Networks, which operate as some of the strongest generators of Big Data (e.g. Social Network Analysis) not only provide fascinating raw material on the social and political preferences of its users (if indeed it could be used as such a research tool), but have been effectively used to generate political outcomes. Attempts by the Chinese Communist Party to restrain the national use of Google to the use Facebook and Twitter during a variety of Arab Spring uprisings, and Egypt's response of cutting off all internet and mobile communication between demonstrators all illustrate the profound ability of interlinked communication to generate a political that is anything but virtual [4]. The sheer range of Big Data's impact is still largely untapped as a tool to further political and governance studies. In response, an MIT project called "Immersion" now makes it more possible for users to experience the entire scope of information gathering and networking analysis possible based merely on ones own email contacts (without even going into the content) [5]. Is this the first cut at turning the insidious nature of Big Data to a more palatable, objective use as the raw empirical data for studies within social and political science? Do we ourselves as researchers see, understand and support the need for this new avenue?

Is Big Data poised to become the raw material of empirical investigation for politics and governance researchers? Does its research utility balance the tremendous power of its market reach? Much remains at odds, from the imbalance of ethics, security, surveillance, and lack of overarching code of conduct to assist in the governance of this troublesome area. Indeed, the most pressing issues to date are the difficulties encountered in governing the use and misuse of Big Data effectively. Would codes of conduct specifically for corporations, and codes of ethics for science and applied research help clarify this area? Watch this space. Carefully...

Policy-The Cable. 24 October 2013. Available from: http://thecable.foreignpolicy.com/posts/2013/10/24/e xclusive_germany_brazil_turn_to_un_to_restrain_ame rican_spies (accessed on 10 January 2014).

4. Richtel M. Egypt Cuts Off Most Internet and Cellphone Service. The New York Times. 28 January 2011. Available from: http://www.nytimes.com/2011/ 01/29/technology/internet/29cutoff.html (accessed on 10 January 2014).

5. Immersion: A People-centric View of Your Email Life. Available from: https://immersion.media.mit.edu (accessed on 10 January 2014). 